\title{
PERANCANGAN SISTEM INFORMASI PENGGUNAAN DANA BANTUAN OPERASIONAL SEKOLAH TERPADU DENGAN METODE BERORIENTASI OBJEK
}

\author{
Hendri Rasminto \\ Program Studi Komputerisasi Akuntansi \\ Sekolah Tinggi Elektronika dan Komputer Semarang \\ Email: hen3_cs@yahoo.com \\ Arsito Ari Kuncoro \\ Program Studi Sistem Komputer \\ Sekolah Tinggi Elektronika dan Komputer Semarang \\ Email: asa.ari@gmail.com \\ Budi Santoso \\ Mahasiswa Program Studi Sistem Komputer \\ Sekolah Tinggi Elektronika dan Komputer Semarang \\ Email: budi_santoso@stekom.ac.id
}

\begin{abstract}
ABSTRAK
Penerapan Teknologi Informasi saat ini telah menyebar hampir di semua bidang tidak terkecuali dalam penggunaan Dana Operasional Sekolah (BOS) mungkin seluruh kegiatan penggunaan dana bantuan operasional memanfaatkan teknologi informasi. Bantuan Operasional Sekolah adalah program pemerintah yang pada dasarnya adalah untuk penyediaan pendanaan biaya operasi nonpersonalia sekolah bagi satuan pendidikan dasar sebagai pelaksana program wajib belajar 9 tahun. Dengan adanya dana Bantuan Operasional Sekolah ini, maka akan lebih meringankan beban para orangtua siswa dengan dihilangkannya biaya SPP bulanan. Masalah yang sering terjadi dalam penggunaan dana bantuan sekolah adalah sistem yang ada sekarang ini masih kesulitan mengontrol anggaran operasional setiap Triwulannya, sehingga masih banyak terdapat anggaran yang melibihi dari anggaran yang ditetapkan sebelumnya di Rencana Kegiatan Anggaran Madrasah (RKAM). Dengan penelitian ini, peneliti merancang sistem informasi Penggunaan Dana Bantuan Sekolah (BOS Terpadu berbasis web dengan Metode Berorientasi Objek menggunakan software Adobe Dreamweaver. Diharapkan TU dan bendahara BOS dalam memberikan informasi penggunaan Dana BOS menjadi lebih terstruktur, lebih baik dan lebih cepat dalam menyusun laporan triwulan, serta mampu menghasilkan informasi dan pelaporan yang tepat dan akurat. Pertimbangan penggunaan web juga sebagai pemantauan langsung komite sekolah dan guru dalam penggunaan Dana Bantuan Sekolah supaya tidak terjadi penyelewengan anggaran, sehingga dengan adanya sistem ini dapat memberikan informasi penggunaan Dana Bantuan Sekolah dengan lebih cepat dan akurat.
\end{abstract}

Kata kunci: sistem informasi, RKAM, BOS, web.

\begin{abstract}
The application of Information Technology has now spread almost in all areas including the use of School Operational Fund (BOS) may be all activities of the use of operational grants utilizing information technology. School Operational Aid is a government program that essentially is to provide funding for nonpersonal school operating costs for basic education units as implementers of the 9-year compulsory education program. With the School Operational Assistance Fund, it will be more ease the burden of the parents with the elimination of monthly fee of SPP. A problem that often occurs in the use of school grants is that the current system still has difficulties controlling the operational budget every quarter so that there is still a substantial budget out of the budget set previously in the Madrasah Budget Activities Plan (RKAM). With this research, researchers designed a system of Information Use Fund Assistance School (BOS) Integrated web-based Object Oriented Method using Adobe Dreamweaver software. It is expected that TU and BOS treasurer in providing information on the use of BOS Funds to be more structured, better and faster in preparing quarterly reports, and able to produce accurate and accurate information and reporting. Consideration of web usage also as direct monitoring of school
\end{abstract}


committee and teacher in School Fund Assistance to avoid budget misappropriation, so that with this system can give information about usage of School Assistance Fund more quickly and accurately.

Keywords: information systems, RKAM, BOS, web.

\section{PENDAHULUAN}

Penerapan Teknologi Informasi saat ini telah menyebar hampir di semua bidang tidak terkecuali dalam pengelolaan Dana Operasional Sekolah. Pada perkembangan ini memungkinkan seluruh kegiatan penggunaan dana bantuan operasional sekolah memanfaatkan teknologi informasi. Kebutuhan akan Teknologi Informasi sangat berhubungan dengan peran dari pengelolaan dana bos sebagai program standar pendidikan yang diperlukan untuk membiayai kegiatan operasi nonpersonalia selama 1 (satu) tahun bagian dari dana pendidikan agar pendidikan dapat melakukan kegiatan pendidikan secara teratur dan berkelanjutan sesuai dengan Standar Nasional Pendidikan. Menurut Sugeng Riyadi, Dari penelitian yang berjudul : "Pengaruh Dana Bantuan Operasional Sekolah Terhadap Peningkatan Manajemen Sekolah " Pengertian dana BOS sendiri adalah program pemerintah untuk penyediaan pendanaan biaya nonpersonalia bagi satuan pendidikan dasar dan menengah sebagai sarana pelaksanaan program wajib belajar 9 tahun. Program BOS bertujuan untuk membebaskan segala jenis biaya pendidikan bagi seluruh siswa SD, SMP negeri dan swasta di Indonesia dari biaya operasion sekolah. [1]

Dengan adanya dana Bantuan Operasional Sekolah ini, maka akan lebih meringankan beban para orangtua siswa dengan dihilangkannya biaya SPP bulanan. Kepala sekolah dan seluruh staf pengajar yang ada juga merasakan kemudahan yang didapat dengan adanya dana Bantuan Operasional Sekolah karena proses yang tadinya dimulai dari mengumpulkan biaya dari tiap siswa, menjadi hanya tinggal melaksanakan dan menggunakan dana yang sudah ada sesuai dengan aturan dan petunjuk penggunaan dari pemerintah mengenai dana Bantuan Operasional Sekolah tersebut, dikarenakan dalam hal pengelolaan dana BOS ini belum menggunakan sistem informasi yang terkomputerisasi, sehingga setiap bagian yang memerlukan informasi tidak bisa dengan cepat mendapatkan informasi yang dibutuhkan, karena pemprosesan data masih dilakukan secara manual, baik itu data siswa yang mendapat dana BOS, data penggunaan dana BOS untuk pos-pos pengeluaran atau pembelanjaan rutin, dan data-data lainnya yang dibutuhkan, beberapa kendala yang terjadi ialah terlalu banyak menghabiskan kertas untuk mencetak laporan sementara, yaitu laporan yang hanya dilakukan pencatatan berasarkan 13 komponen yang ada didalam buku petunjuk teknis BOS, [4]. jika terjadi pembelanjaan anggaran belum memenuhi target maka akan dilakukan kembali pencatatan ulang dan mengelompokkan kembali kwitansi-kwitansi pembelian barang dan jasa sesuai dengan 13 komponen pembelanjaan bos.

Dari uraian di atas memberikan gambaran bahwa sistem yang ada sekarang ini masih kesulitan mengontrol anggaran operasional setiap Triwulannya, sehingga masih banyak terdapat anggaran dana bantuan operasional sekolah yang melibihi dari anggaran yang di tetapkan sebelumnya di Rencana Kegiatan Anggaran Madrasah (RKAM), ini akan berdampak terhadap Program Pemerintah dengan tidak terpenuhinya Program 8 Standar Pendidikan Nasional yang terdiri dari Pengembangan Standar isi Pengelolaan Kurikulum, Pengembangan Standar Proses, Pengembangan Standar Kelulusan, Pengembangan Standar Pendidik dan Tenaga Kependidikan, Pengembangan Standar Sarana dan Prasarana, Pengembangan Standar Pengelolaan, Pengembangan Standar Pembiayaan, dan Pengembangan Standar Penilaian [3].

Menurut Ines Desti Indraswuri, Sukadi, dari Jurnal Yang Berjudul : “Analisis Dan Perancangan Sistem Informasi Pelaporan Bantuan Operasional Sekolah Unit Pelaksana Teknis Taman Kanak-Kanak Dan Sekolah Dasar", selain memaparkan kajian teori yang digunakan sebagai dasar penyusunan, juga akan dibahas mengenai wawancara, analisis dan perancangan sistem. Sehingga dapat diharapkan dapat diimplementasikan dalam sebuah produk yang akan memperbaiki segala kekurangan pada system yang lama [2], sehingga dengan membangun sistem informasi pengelolaan dana BOS terpadu dengan metode Berorientasi Objek [6] dapat meningkatkan penggunaan anggaran bantuan Operasional Sekolah agar tepat dan akurat pada Komponen Program 8 Standar Pendidikan Nasional yang terdapat didalam Buku Petunjuk Teknis (Juknis) BOS sesuai tahun anggaran yang berlaku. Manfaat yang ingin dicapai adalah supaya sistem yang dibangun bisa digunakan untuk mempermudah pekerjaan dalam pengelolaan dana anggaran bantuan operasional. [4].

\section{METODOLOGI PENELITIAN}

Model pengembangan dalam penelitian ini menggunakan pendekatan penelitian dan pengembangan Research and Development (R\&D). Borg \& Gall mengungkapkan bahwa siklus R\&D tersusun dalam beberapa langkah penelitian yaitu : Research and information collecting, Planning, Develop preliminary 
form of product, Preliminary field testing, Main product revision, Main field testing , Operational product revision, Operational field testing, Final product revision, Dissemination and implementation. Dalam penelitian ini dari 10 langkah tersebut yang akan digunakan hanya 6 langkah. Penjelasan dari 6 langkah tersebut sebagai berikut :[5]

a. Research and information collecting, termasuk dalam langkah ini antara lain studi literatur yang berkaitan dengan permasalahan yang dikaji.

b. Planning, termasuk dalam langkah ini menyusun rencana penelitian yang meliputi merumuskan kecakapan dan keahlian.

c. Develop preliminary form of product, yaitu mengembangkan bentuk permulaan dari produk yang akan dihasilkan.

d. Preliminary field testing, yaitu melakukan ujicoba lapangan awal dalam skala terbatas, 12 subyek. Pada langkah ini pengumpulan dan analisis data dapat dilakukan dengan cara wawancara, observasi atau angket.

e. Main product revision, yaitu melakukan perbaikan terhadap produk awal yang dihasilkan berdasarkan hasil ujicoba awal.

f. Main field testing, biasanya disebut ujicoba utama yang melibatkan khalayak lebih luas.Pengumpulan data dilakukan secara kuantitatif, terutama dilakukan terhadap kinerja sebelum dan sesudah penerapan ujicoba.

Langkah-langkah penelitian lebih jelasnya dapat dilihat pada gambar 1. berikut ini :

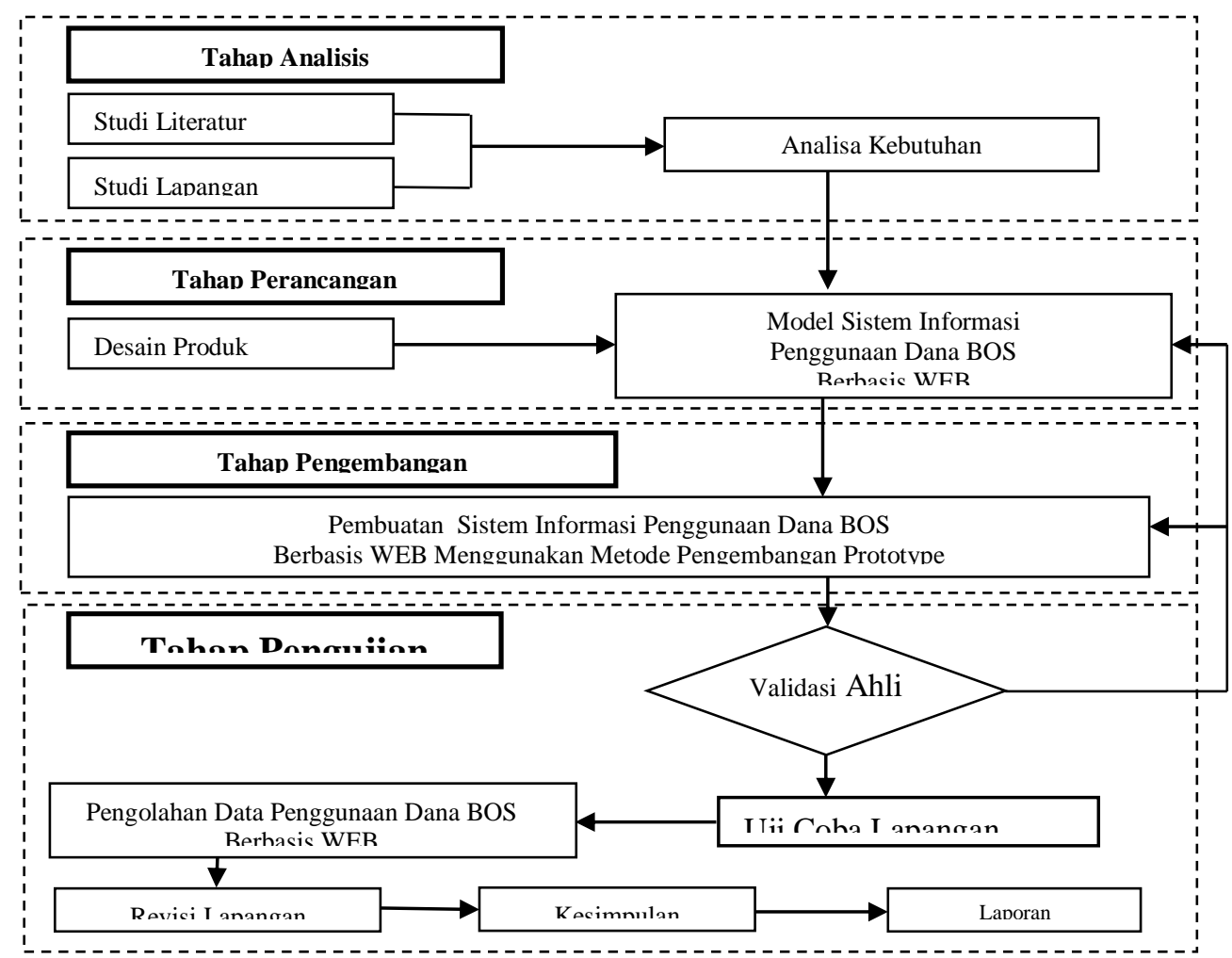

Gambar 1. Langkah-Langkah Penelitian

Keterangan dari langkah-langkah diatas sebagai berikut:

a. Tahap Analisis

1. Survei Lapangan

Survei lapangan merupakan langkah awal yang bertujuan untuk memperoleh data yang dibutuhkan dalam tahap analisis. Pada tahap ini peneliti melakukan tanya jawab ditempat penelitian untuk mengetahui alur dari suatu proses Penggunaan BOS yang sedang berjalan pada MTs yang penulis teliti.

2. Studi Pustaka

Studi pustaka merupakan kegiatan mengumpulkan data-data berupa teori pendukung dari sistem yang dibuat dengan maksud untuk memaparkan tentang teori-teori yang berhubungan 
dengan sistem informasi Penggunaan BOS yang berbasis web. Sumber-sumber yang didapat berupa literatur, jurnal, ebook, dan lainnya yang relevan dengan penelitian.

b. Tahap Perancangan

Pada tahap ini akan dilakukan perancangan model seperti pembuatan program, pemilihan database, pemilihan jaringan yang sesuai pada permasalahan pada obyek penelitian.

c. Tahap Pengembangan

Pada tahap ini, tools pengembangan digunakan untu mengimplementasikan sistem agar terkoneksi dengan jaringan internet. Pada tahap ini sistem menggunakan model pengembangan prototype. Tahapan-tahapan dalam pengembangan Prototype, antara lain: tahap mengidentifikasi kebutuhan pemakai, tahap membangun, tahap penggujian, dan tahap penggunaan

d. Tahap Pengujian

1. Pengujian Sistem

Pengujian adalah elemen kritis dari jaminan kualitas dan merepresentasikan spesifikasi, desain dan pengkodean. Dalam melakukan uji coba ada dua masalah penting yang akan dibahas, yaitu teknik dan strategi.

2. Verifikasi dan Validasi Sistem

Verifikasi dan validasi sistem oleh tim ahli bertujuan untuk menguji kelayakan dan rasional sistem oleh praktisi yang berhubungan dengan penelitian. Langkah ini dilakukan dengan menggunakan format uji sistem

3. Revisi dan Review Sistem

Setelah verifikasi dan validasi oleh tim ahli, maka akan dilakukan revisi dan review yang dimaksudkan agar sistem sudah memiliki kelayakan dan fungsional yang baik untuk menjadi sebuah sistem yang layak. Pada tahap ini akan melihat kembali produk yang dihasilkan, dilihat dari kelayakan sistem informasi pengendalian persediaan yang dihasilkan, serta kekurangan, kelebihan, kendala dan rekomendasi.

4. Implementasi Sistem

Uji coba produk dilakukan terbatas. Uji coba akan dilakukan pada bagian Bendahata MTs Raden Sahid Mangunan Lor, Untuk penilaian terhadap sistem yang telah penulis buat.

5. Analisis Hasil

Hasil Dari tahap implementasi sistem akan dianalisa dan kemudian akan dilakukan pemeliharaan terhadap sistem. Pemeliharaan sistem dapat meliputi aktivitas koreksi kesalahan, adaptasi, peningkatan sistem dan perekayasaan kembali.

Secara khusus metode pengembangan Prototype dapat dijelaskan dalam tahapan-tahapan sebagai berikut: (dijelakan di Gambar 5).

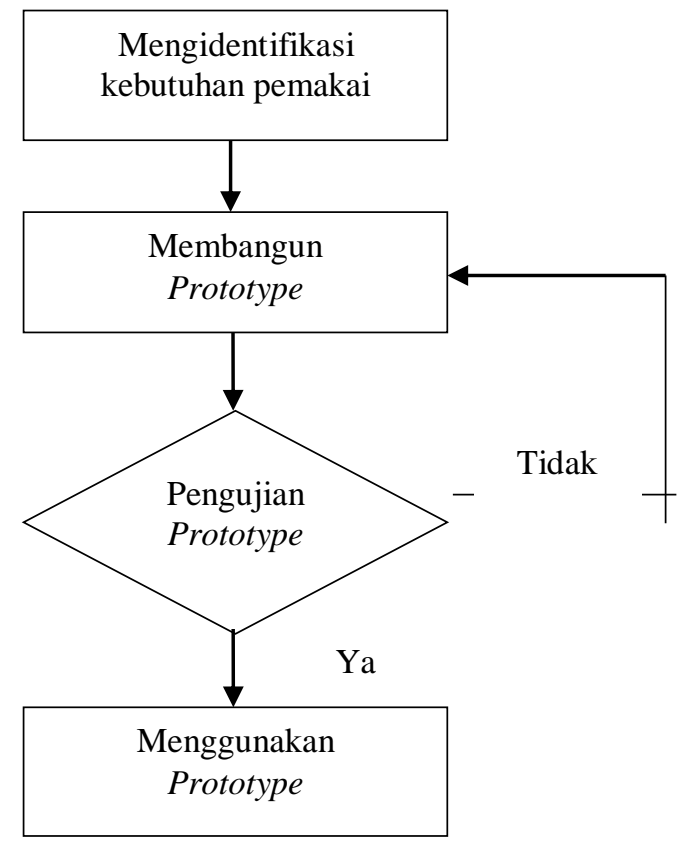

Gambar 2. Diagram Alir Metode Pengembangan Sistem Prototyping 
a. Tahap mengidentifikasi kebutuhan pemakai

Melakukan penelitian lapangan untuk mendapatkan data-data dan informasi yang dibutuhkan dengan cara:

1) Mengamati secara langsung sistem informasi Penggunaan BOS berbasis web di MTs Raden Sahid Mangunan Lor, termasuk sistem yang digunakan pada saat ini, pencatatan, pembuatan laporan, kelemahan-kelemahan dari sistem yang ada dan sebagainya, yang nantinya bisa menjadi pedoman dalam pembuatan sistem

2) Melakukan wawancara dengan bagian Bendahara MTs Raden Sahid Mangunan Lor. Hal ini dilakukan guna memperoleh informasi-informasi yang dibutuhkan untuk memperoleh gambaran spesifikasi produk yang diharapkan oleh sekolah.

3) Melakukan studi literatur guna mendapatkan teori-teori utama yang menunjang dalam rancang bangun sistem.

4) Memilih metode penyelesaian yang tepat berdasar pengamatan dan keinginan calon pemakai dengan mempertimbangkan biaya yang murah dan teknologi yang sesuai untuk diterapkan.

b. Tahap Membangun

Membangun prototype berdasar analisis kebutuhan, dimana pada tahap ini akan dimulai dengan perancangan spesifikasi sistem, perancangan perangkat lunak dengan alat bantu perancangan seperti:

1) Merancang detail sistem

Untuk memberikan sistem yang terancang secara rapi dapat mengggunakan alat bantu berupa flowchart, Normalisasi, DFD, ERD, dan perancangan database serta perancangan form-form tampilan input dan output dan perancangan fisik jaringan Multiuser.

2) Membuat program

Langkah berikutnya dilanjutkan dengan pembuatan source code dengan software Adobe

Dreamweaver CS5.

c. Tahap Pengujian

Pengujian prototype dilakukan dengan menggunakan beberapa komputer yang dapat terhubung dengan jaringan internet, yaitu memberi kesempatan pada validator pakar untuk melakukan pengujian dan memberikan masukan-masukan apabila prototype yang dibuat masih ditemukan kekurangan atau kelemahan oleh pakar, dan prototype akan direvisi sesuai kekurangan yang ada, kemudian diujikan kembali sampai dinyatakan lulus uji validasi oleh pakar. Pengujian kedua dilakukan di tempat penelitian, yaitu uji validasi dilakukan oleh stakeholder dalam hal ini diwakili oleh bagian bendahara di MTs Raden Sahid Mangunan Lor. Apabila masih ditemukan kelemahan/kekurangan dari hasil pengujian, maka akan diperbaiki sampai dinyatakan lulus uji validasi.

d. Tahap Penggunaan

Setelah pengujian oleh Validator dan dinyatakan tidak ada masalah lagi maka prototype tersebut dinyatakan lulus uji validasi dan bisa digunakan secara terbatas, serta akan mendapat pengesahan dari kedua validator tersebut.

\section{HASIL DAN PEMBAHASAN}

Dalam tahap ini akan dilakukan identifikasi perkiraan kebutuhan pemakai dan juga mempelajari literatur dan meneliti lebih terperinci tentang permasalahan yang ada pada sekolah. Penelitian awal dilakukan untuk mendapatkan informasi kebutuhan dalam penelitian. Proses pengembangan diawali dengan pembuatan database RKAM dengan mysql, kemudian penyusunan project baru menggunakan Adobe Dreamweaver CS3, penggunaan XAMPP 1,8.2 server sebagai localhostnya [7], selanjutnya penyusunan menu utama kemudian menyusun form-form untuk input data, penerimaan, RKAM, Pengeluaran dan laporan. Berikut adalah hasil produk akhir setelah penulis melakukan uji validasi yang melibatkan pakar ahli dan user:

a. Tampilan Form Login Petugas

Tampilan sebelum Petugas TU masuk sistem adalah Tampilam login Petugas, yang terdiri dari User ID dan password. Login dibuat dengan hak akses yang berbeda-beda dengan memasukkan User ID dan password masing-masing sesuai jabatan. Apabila User ID dan password sesuai maka halaman utama akan aktif dan menu-menu yang ada juga akan aktif sesuai hak akses masing-masing. Tampilan gambar 5. adalah form login petugas dapat dilihat pada gambar dibawah ini : 


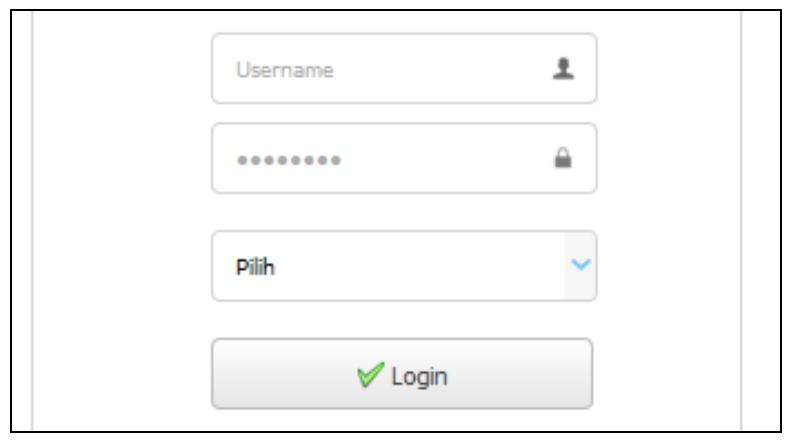

Gambar 3. Tampilan Form Login Petugas

b. Tampilan Form Halaman Utama Petugas

Halaman Utama Petugas merupakan form yang muncul setelah petugas melakukan Login. Jika login dengan hak akses Username Biasa maka Menu User tidak akan tampil, sedangkan jika Login dengan hak akses Username dan pilihanya Tata usaha maka Menu User akan muncul, dikarenakan hanya petugas dengan hak akses User dapat melakukan Input Data untuk petugas lain berdasarkan hak akses. Gambar 4. adalah Form ini juga menampilkan informasi kinerja guru. Tampilan Form Halaman Utama Petugas dapat dilihat pada gambar dibawah ini :

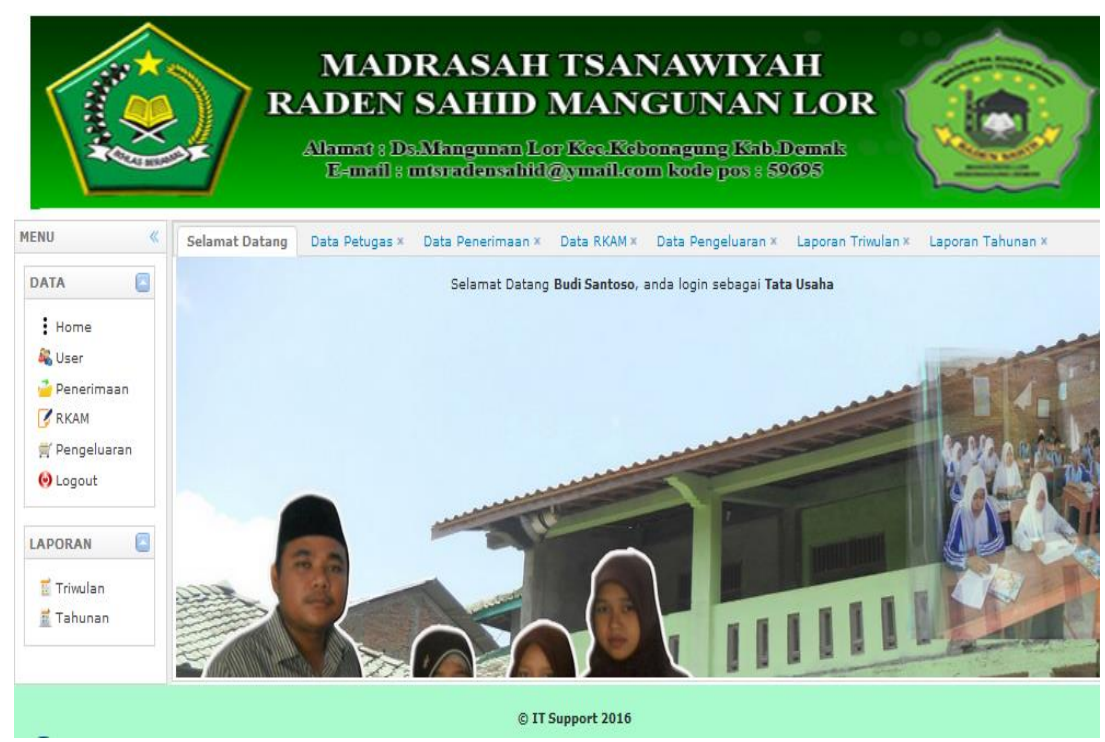

Gambar 4. Tampilan Form Halaman Utama

c. Tampilan Form Petugas

Gambar 5. adalah Form ini digunakan untuk menampilkan data petugas. Tampilan Form Input Data petugas dapat dilihat pada gambar dibawah ini : 


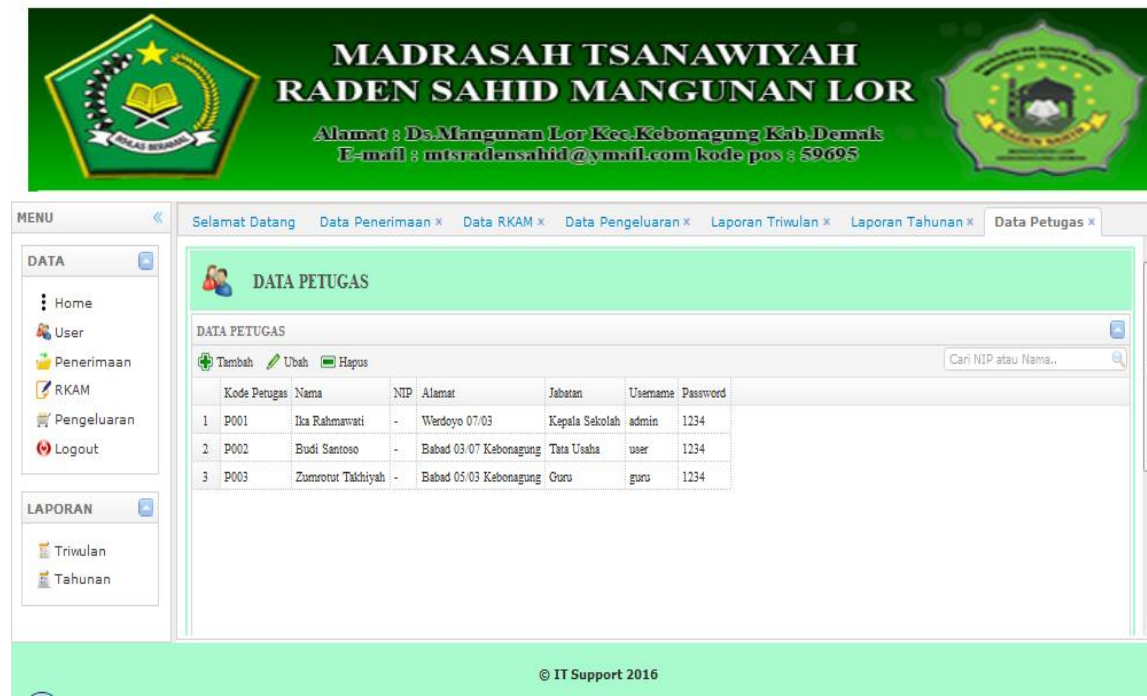

Gambar 5. Tampilan Form Input Data Petugas

d. Tampilan Form Penerimaan

Gambar 6. adalah Form digunakan untuk menampilkan data penerimaan. Tampilan Form Input Data penerimaan dapat dilihat pada gambar dibawah ini :

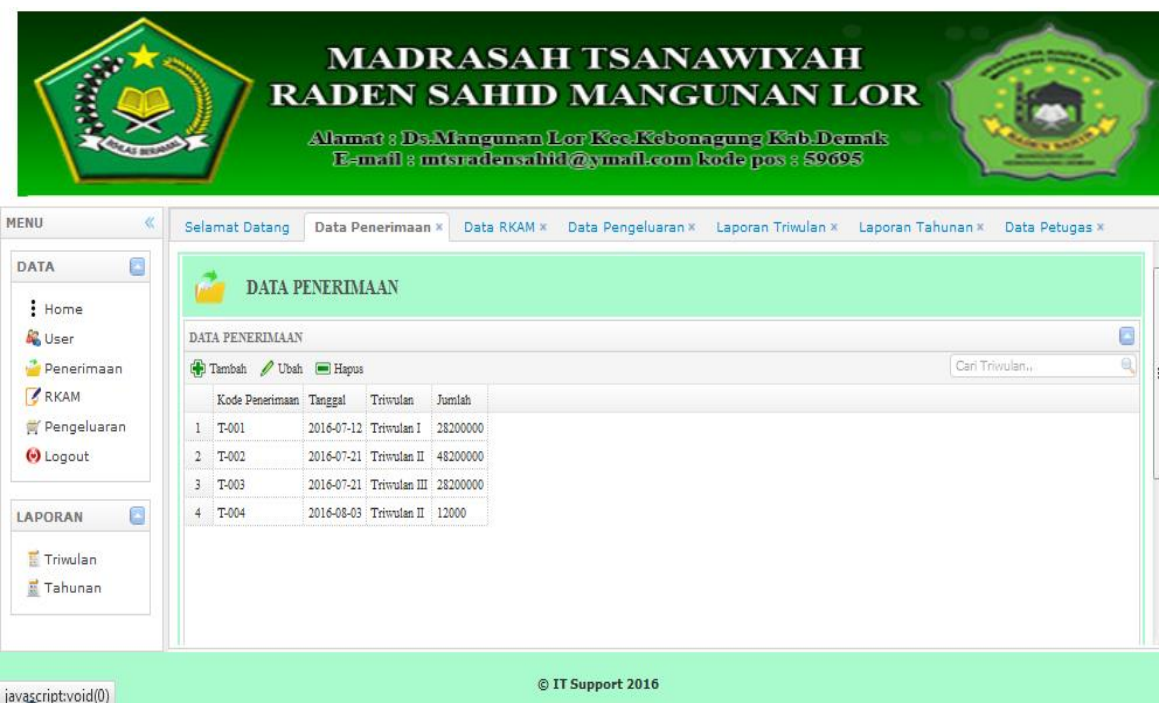

Gambar 6. Tampilan Form Penerimaan

\section{KESIMPULAN}

Berdasarkan penelitian, pengujian dan penyusunan skripsi dengan judul " Sistem Informasi Penggunaan Dana Bantuan Sekolah Berbasis Web Di MTs Raden Sahid Mangunan Lor Kecamatan Kebonagung Kabupaten Demak", maka penulis dapat menarik beberapa kesimpulan, antara lain sebagai berikut:

a. Sistem Informasi Penggunaan Dana Bantuan Sekolah yang dilakukan di MTs Raden Sahid Mangunan Lor menggunakan sistem komputerisasi Tapi Informasinya masih kurang jelas.

b. Dengan dibangunya sistem informasi Penggunaan Dana Bantuan Sekolah yang berbasis web dapat mempercepat proses input data pengeluaran dan laporan, memperkecil resiko kehilangan data.

c. Sistem informasi yang dibangun dapat memudahkan petugas dalam membuat laporan Triwulan dan Tahuanan. 


\section{DAFTAR PUSTAKA}

[1] Sugeng Riyadi, 2010 "Pengaruh Dana Bantuan Sekolah Terhadap Peningkatan Manejemen Sekolah" STAIN Ponorogo.

[2] Ines Desti Indraswuri,Sukadi, 2013. “ Analisis Dan Perancangan Sistem Informasi Pelaporan Bantuan Operasional Sekolah Unit Pelaksana Teknis Taman Kanak-Kanak Dan Sekolah Dasar (UPT TK Dan SD) Kecamatan Kebonagung. Universitas Surakarta.

[3] Al-Jufri, 2011; “SISTEM INFORMASI MANAJEMEN PENDIDIKAN”, Jakarta: Smart Grafika.

[4] Kemdiknas; 2010; "Buku Panduan Bantuan Operasional Sekolah (BOS) Untuk Pendidikan Gratis dalam Rangka Wajib Belajar 9 Tahun yang Bermutu.

[5] Borg, Walter R., \& Gall, M.D, 1983; "EDUCATIONAL RESEARCH: AN INTRODUCTION (4ED)”, New York \& London : Longman.

[6] Sudirman, Eko Retnadi, Rina Kurniawati, 2012, "Perancangan Program Aplikasi Transaksi Pembayaran SPP, UTS dan UAS Menggunakan Metode Analisis dan Desain Berorientasi Objek Model Unified Approach (UA)". ISSN: 2302-7339 Vol. 09 No 182012.

[7] Anhar, 2010; "PANDUAN MENGUASAI PHP DAN MYSQL SECARA OTODIDAK", Jakarta: Media Kita. 